Brit. J. vener. Dis. (1956), 32, 162.

\title{
RADIOLOGY IN LATE CONGENITAL SYPHILITIC NERVE DEAFNESS $*$
}

\author{
BY \\ R. S. MORTON \\ Stockport and East Cheshire
}

It is now nearly 100 years since Hutchinson (1863) described the triad of symptomatology in congenital syphilis. The notched incisors which he described have never been a problem because if found aesthetically unacceptable to the patient, they can be extracted and replaced by a prosthesis. Interstitial keratitis can now be controlled by topical cortisone. Therefore, the time seems ripe to turn our attention to the third component of the triad-the nerve deafness.

Ritchie Rodger (1945) classified deafness in congenital syphilis into early and late types. He gave two varieties of the early type: a neuritis associated with basal meningitis and an oto-labyrinthitis. These two early varieties occur in infancy. There is only one late type, a labyrinthitis, which is by far the commonest and it is to this late variety that the present paper refers.

This labyrinthitis usually occurs after the age of 8 years, and may appear at any period of adult life. Onset may be sudden and deafness total, although in some cases the affection starts mildly to progress rapidly or slowly. The deafness is usually bilateral, and is more common in females. Complaints of tinnitus and/or vertigo may herald, follow, or be co-existent with the deafness. Late nerve deafness is often associated with other stigmata of congenital syphilis, particularly interstitial keratitis, and appears sometimes before but more generally after them. Like interstitial keratitis the deafness is not influenced by anti-syphilitic treatment, and may appear during or after adequate therapy.

In the series of cases described by Ritchie Rodger (1945), deafness occurred in 44 of 121 (36 per cent.) of congenital syphilitics, although as an aural specialist, his series must be regarded as selected.

* Received for publication March 21, 1956.

tShort paper read before the M.S.S.V.D. on February 24, 1956
Forty of these 44 cases had interstitial keratitis. Nabarro (1955) reports about 4 per cent. nerve deafness in $\mathbf{4 6 5}$ congenital syphilitics, but here again the series is selective as his patients are mainly children. The generally accepted figure of incidence is 10 per cent. of congenital syphilitics (Stokes, Beerman, and Ingraham, 1944).

Ritchie Rodger apart, the only other outstanding contribution since Hutchinson's time has been that of Mayer and Fraser (1936), who reported the postmortem findings in a few cases of late congenital syphilitic nerve deafness. They described a serous labyrinthitis which they believed to be consequent on periostitis and osteitis in the bone surrounding the cavities and canals of the internal ear. Microscopically, they believed the lesions to be miliary gummata. More recently Nager (1955) has described similar post-mortem findings in two further cases, although he was unable to state beyond all doubt that the microscopic changes were exclusively syphilitic. The bone changes described in these reports were not by any means extensive. The number of reports is few as, by the very nature of the conditions, post-mortem material is scarce. It, therefore, seemed reasonable to approach the problem from another angle.

Several papers have been published describing the radiological findings in the petrous part of the temporal bone in chronic suppurative otitis media (Taylor, 1939; Graham-Hodgson, 1950). In this condition the petrous pyramids often show diminution of pneumatization with generalized sclerosis. These changes follow destructive.lesions, and the remaining trabeculae show thickening.

I have been unable to find any trace in the literature regarding a similar approach to the problem of late congenital syphilitic nerve deafness.

Radiological examination of the petrous temporals 


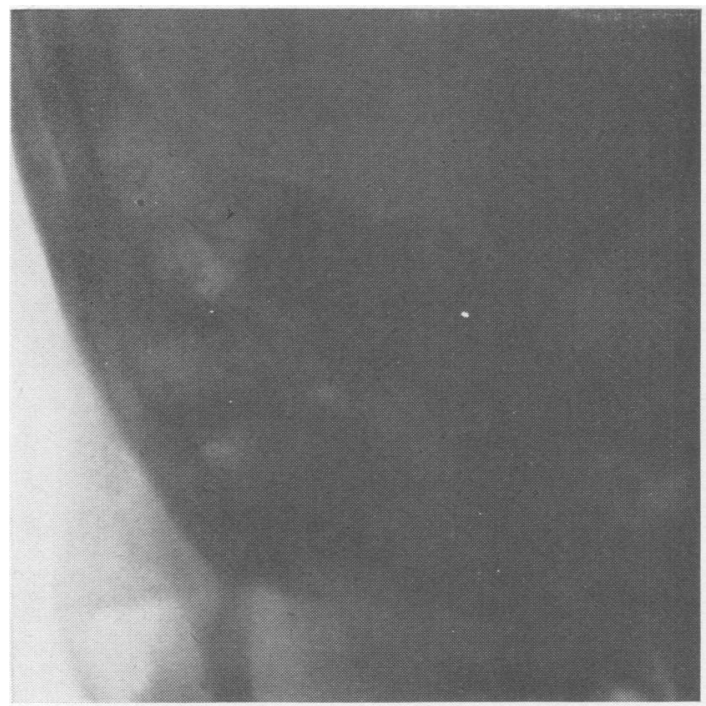

Fig. 1.-Right half Towne's view_of petrous temporal bone.

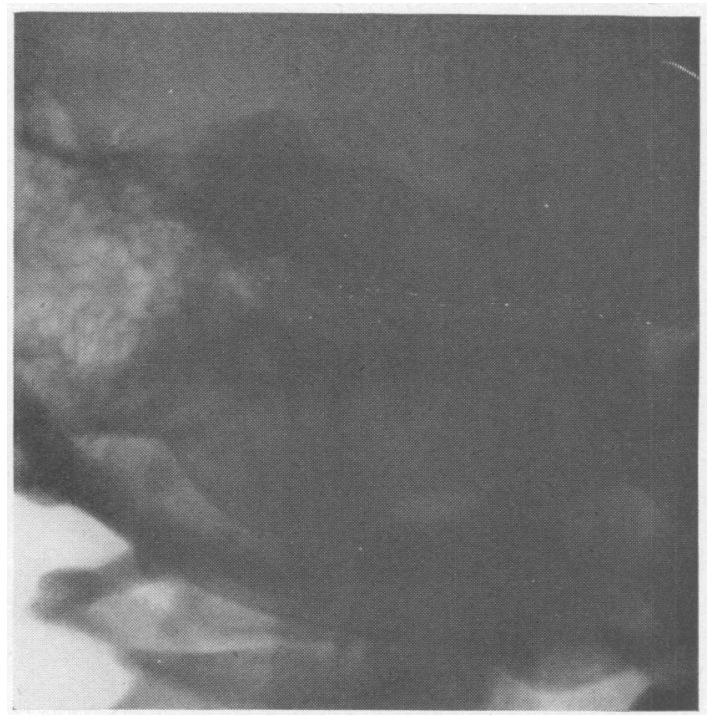

Fig. 2-Stenver's view of left petrous temporal bone.

is not easy, as from all angles there is always intervening bone. Two approaches to the radiographic problem are in general use-Towne's and Stenver's. In Towne's view both petrous bones are seen simultaneously on the same film and the view gives reasonable definition of the inner ear (Fig. 1). The patient in this view is placed supine on the table. The face is uppermost and the orbito-meatal line at an angle of $90^{\circ}$ to the table top. The tube is angled at 25 to $35^{\circ}$ towards the feet, centring midway between the

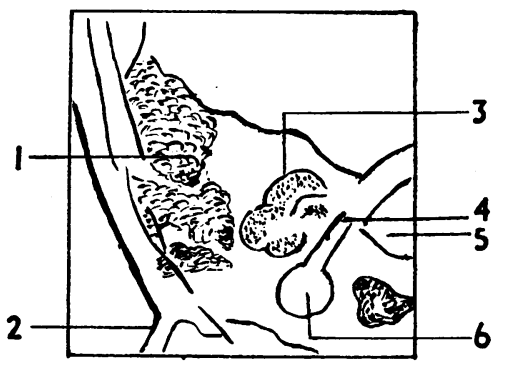

(1) Mastoid air cells.

(2) Lateral wall maxillary sinus.

(3) Area of semi-circular canals.

(4) Internal auditory canal.

(5) Foramen magnum.

(6) Cochlea.

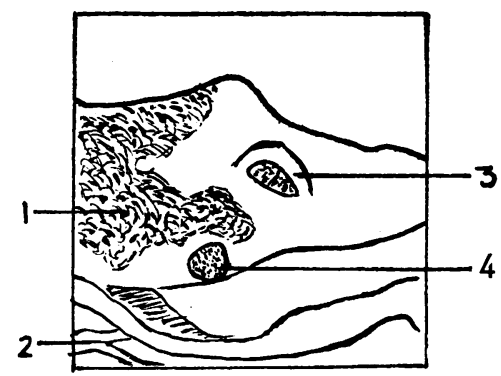

(1) Mastoid air cells.

(2) Lateral process first cervical vertebra.

(3) Superior semicircular canal.

(4) Internal auditory canal.

mastoid processes and to the centre of the film.

Stenver's view shows only one petrous bone (Fig. 2) but it does sometimes give a better view of the internal ear than Towne's view. It is, however, more difficult to obtain and the results are more variable. The view is obtained by placing the patient prone, and rotating the head $45^{\circ}$ either to the right or to the left. The tube is angled at 10 to $12^{\circ}$ towards the head and the centring point is the mastoid process to the centre of the film. 


\section{Material}

In the present series 46 congenital syphilitics were invited to cooperate in the study, and forty did so. The average age of the patients examined was 25 with extremes of 9 and 53 years. There were 25 females and fifteen males. Six of the patients (five females and one male) had nerve deafness. Two of the deaf patients had a history of interstitial keratitis.

In no case was any significant radiological change seen in the appearance of the semicircular canals, cochleae, or internal auditory canals, or in the bone adjacent to these structures. In the majority of cases films were compared with views of non-syphilitic skulls. In five cases there was - a doubtful increase in the density of the petrous bones, but this was very much a matter of opinion. Only one of these was deaf. In one patient who had had recurrent chronic suppurative otitis media over the last 2-3 years, definite sclerosis of both petrous bones was found.

Tomography was also used in some of the deaf patients to obtain better visualization of the internal ear, but it has not yielded any more information than the two standard projections.

\section{Discussion}

In the light of the post-mortem findings it was hoped that positive radiological results would be found in the deaf patients, and that similar findings in other congenital syphilitics would give some indication as to which congenital syphilitics were likely to become deaf. If, as Mayer and Fraser (1936) suggest, the deafness is the end result of gummatous periostitis and osteitis in the bone surrounding the inner ear, why are the changes so restricted as to be unidentifiable on $x$ ray? Very restricted syphilitic bone lesions especially in the skull are unusual. Why should they be so universally unusual in the petrous bone? It may be, of course, that the negative nature of the radiological findings is of itself significant, and I feel that there is something here, however little, to support my suggestion (Morton, 1955) that late congenital syphilitic nerve deafness is a hypersensitivity phenomenon. We have already seen how nerve deafness is as ubiquitous as interstitial keratitis. The two are commonly associated. We know that interstitial keratitis is controlled by cortisone. It is possible that cortisone treatment given early in late congenital nerve deafness may be useful. This presages early diagnosis and the fullest cooperation of our E.N.T. colleagues. Rodger (1945) has said that the commonest age of onset of deafness is 8-15 years. In the years 1945-48 early syphilis was at its peak in Great Britain. It is possible then that the earliest cases of late congenital syphilitic nerve deafness in patients who were born in the years mentioned, may present themselves over the next few years. Congenital syphilitic patients already treated, especially where intersitial keratitis was the presenting symptom, are also potential candidates for deafness. The opportunity may therefore be at hand to try cortisone therapy.

Since cases are likely to be restricted in number, the Cooperative Clinical Group of our Society might consider a nation-wide research trial with a view to early assessment of results.

\section{Summary}

Forty congenital syphilitics, including six with late congenital syphilitic nerve deafness, have had their petrous temporals examined radiologically. The results are substantially negative.

These negative findings seem to support the suggestion that late congenital syphilitic nerve deafness is a hypersensitivity phenomenon.

Further research is indicated.

My thanks are due to my radiological colleagues Drs. A. Griffiths and D. M. Coates for their cooperation and criticism.

\section{REFERENCES}

Graham-Hodgson, H. (1950). Proc. roy. Soc. Med., 43, 989.

Hutchinson, J. (1863). "A Clinical Memoir on Certain Diseases of the Eye and Ear, Consequent on Inherited Syphilis." Churchill, London. Quoted by Rodger (1945).

Mayer, O., and Fraser, J. S. (1936). J. Laryng., 51, 683, 755.

Morton, R. S. (1955). British Journal of Venereal Diseases, 21, 242. Nager, F. R. (1955). Pract. oto-rhino-laryng. (Basel), 17, 1.

Rodger, T. Ritchie (1945). British Journal of Venereal Diseases, 21, 115 .

Stokes, J. H., Beerman, H., and Ingraham, N. R. (1944). “Modern Clinical Syphilology." Saunders, Philadelphia, p. 1118.

Clinical Syphilology." Saunders,
Taylor, H. K. (1939). Radiology, 33, 79. 